\title{
Cleanliness Validation of NIF Small Optics
}

R. Chow, R. Bickel, J. Ertel, J. Pryatel, G. Loomis, I. Stowers, J.R. Taylor

This article was submitted to Optical Society, Optical System Contamination: Effects, Measurements and Control VII, Seattle, WA, July 10-11, 2002

\section{May 7, 2002}

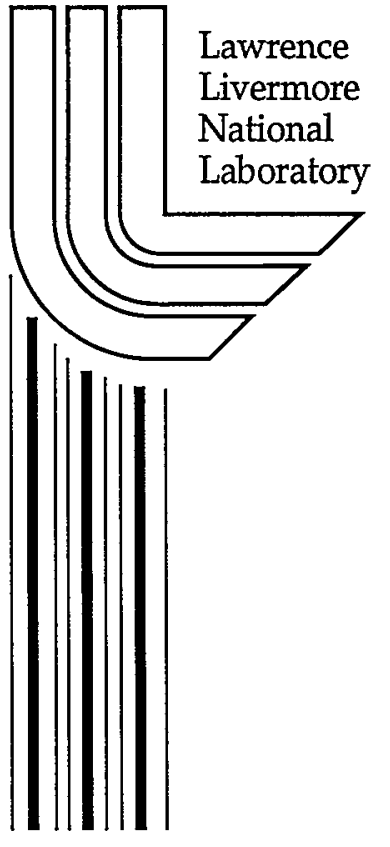




\section{DISCLAIMER}

This document was prepared as an account of work sponsored by an agency of the United States Government. Neither the United States Government nor the University of California nor any of their employees, makes any warranty, express or implied, or assumes any legal liability or responsibility for the accuracy, completeness, or usefulness of any information, apparatus, product, or process disclosed, or represents that its use would not infringe privately owned rights. Reference herein to any specific commercial product, process, or service by trade name, trademark, manufacturer, or otherwise, does not necessarily constitute or imply its endorsement, recommendation, or favoring by the United States Government or the University of California. The views and opinions of authors expressed herein do not necessarily state or reflect those of the United States Government or the University of California, and shall not be used for advertising or product endorsement purposes.

This is a preprint of a paper intended for publication in a journal or proceedings. Since changes may be made before publication, this preprint is made available with the understanding that it will not be cited or reproduced without the permission of the author.

This report has been reproduced directly from the best available copy.

Available electronically at http://www.doc.gov/bridge

Available for a processing fee to U.S. Department of Energy

And its contractors in paper from

U.S. Department of Energy

Office of Scientific and Technical Information

P.O. Box 62

Oak Ridge, TN 37831-0062

Telephone: (865) 576-8401

Facsimile: (865) 576-5728

E-mail: reports@adonis.osti.gov

Available for the sale to the public from

U.S. Department of Commerce

National Technical Information Service

5285 Port Royal Road

Springfield, VA 22161

Telephone: (800) 553-6847

Facsimile: (703) 605-6900

E-mail: orders@ntis.fedworld.gov

Online ordering: http://www.ntis.gov/ordering.htm

OR

Lawrence Livermore National Laboratory

Technical Information Department's Digital Library

http://www.llnl.gov/tid/Library.html 


\title{
Cleanliness Validation of NIF Small Optics
}

\author{
Robert Chow, Robert Bickel, John Ertel, Jim Pryatel, \\ Gary Loomis, Irv Stowers, John R. Taylor \\ LLNL, National Ignition Facility, Livermore, CA
}

\begin{abstract}
The National Ignition Facility will be the highest energy laser in the world when completed. Many small optics ( $\leq$ 14 " in diameter) have stringent transport efficiency and some have very high laser fluence requirements. For optics to sustain high spectral efficiencies and survive high fluences for a 30-year operation, these optics have cleanliness requirements to assure optimal laser system performance. These optical components have insufficient surface areas to validate the particulate and organic contamination requirements by methods used for mechanical parts. Also, the common validation techniques require some sort of surface contact which is not compatible with handling of laser optics. This presentation describes alternate cleanliness validation methods developed for the NIF small optical components. An organic validation procedure was devised based on the spectral transmission sensitivity to contamination layers on coated and uncoated fused silica windows. Optics were scanned in the near infrared before and after an application of a specific amount of organic contamination onto the surface. Changes in transmission correlated to organic contamination levels and used to determine non-volatile organic contamination optics. A validation method for particulate contamination was demonstrated on a large window, showing that acceptable cleanliness levels could be achieved after a wet-wipe and inspection with a high intensity light. The method is similar to that used to inspect the surface quality of optical components.
\end{abstract}

Keywords: Optical cleanliness, non-volatile residues, particulates

\section{INTRODUCTION}

The National Ignition Facility (NIF) is a project funded through the Department of Energy. The NIF Project is designed as a 192-beam, 1.8 MJ experimental laser facility. This unique facility will be able to create environments of extreme pressures and temperatures. The NIF will be able to conduct high pressure/temperature experiments for the national security, energy, and basic science community. The conventional part of the NIF building was completed in 2001. After the installation of the laser beam transport infrastructure and support equipment, the building will be available for deployment of optical components. Figure 1 shows a perspective of the NIF facility taken in December, 2001. 
The NIF cleanliness requirements for small optics are stringent. Organic contamination levels range from $\mathrm{A} / 10$ to $\mathrm{A}$ which correspond to non-volatile residue (NVR) levels of $0.1 \mathrm{microgr} / \mathrm{cm}^{2}$ to $1 \mathrm{microgr} / \mathrm{cm}^{2}$. Particulate contamination levels acceptable for NIF optics range from Level 50 to Level 300, which correspond to surface concentration of particles greater than a 5 micron diameter of 166 to 170,000 per square foot [1]. NIF cleanliness requirements are designed to maintain the pristine conditions of the high-performance laser optics. Contamination degrades the optics by increasing scatter and lowering the laser damage thresholds. Scattering lowers the throughput capacity of the $1.9 \mathrm{MJ}$ laser. Lower laser damage thresholds increases the refurbishment cost of the optics. The NIF also has sol-gel coated optics which easily getter organic molecules via capillary action. Contaminated sol-gel coatings would also impair the performance of the laser system.

The project has established some procedures to validate the cleanliness of metal surfaces. Organic cleanliness levels may be determined by rinsing metal surfaces with solvent (generally 1,1,2 tri-fluorotrichloroethane) and weighing the residue left in the solvent after evaporation to dryness (the NVR) [2]. The particulate cleanliness levels on metal surfaces may be verified by counting particles ( $>5$ microns) concentrated a piece of filter paper that was dragged across the metal part with a swipe tool [3]. The sensitivity of the cleanliness measurement can be controlled by the area of the metal surface that is sampled. Optics, especially small optics, have relatively smaller surface areas than the surrounding mounts and infrastructure walls. In addition, general practice precludes handling of the optical surfaces after coating. This leaves the cleanliness validation of the optical surfaces as an open issue.

The NIF cleanliness group has teamed with the small optics production staff to determine practical validation methods. These validation methods had to be such that they can be performed at the locations supplying the laser optics without undue cost increases and schedule delays.

\section{EXPERIMENTAL}

\subsection{Organic Contamination}

The spectroscopic test for organic contamination on optics is based on the hypothesis that a contaminating layer of uniform thickness may affect the spectral performance of an optic. An anti-reflective coating was designed and optimized for low reflectance at $1053 \mathrm{~nm}$ and zero degree angle-of-incidence. Various thicknesses of an organic, NVR layer were added to the surface of this AR coating design. Assuming that hydrocarbon oils have a refractive index of about 1.3, the reflectance of the coating plus the fraction of a quarter-wave optically-thick (QWOT) layer of NVR was calculated. In Figure 2, the reflectance of the uncontaminated and contaminated coatings are plotted as predicted from the optical design program. The "No NVR" data is the optimized AR coating and is hidden beneath 
the data from the NVR layer that was $0.001 *$ QWOT. An observable reflectance difference was observed when the fraction of the NVR layer reached 0.01 , about $8 \mathrm{~nm}$ in physical thickness. The reflectance curves move to longer wavelengths and higher reflectivities as the coated surface becomes more contaminated. There is reason to believe that low levels of NVR can be detected with spectroscopic tools typical in the optical coatings industry.

In order to establish the relationship between NVR on an optic and transmission change, controlled amounts of organic contaminant, dioctylphthalate (DOP), were spun-deposited onto one side of fused silica optics. Five of the optics were uncoated, super-polished substrates and five other samples were coated with an anti-reflective dielectric coating, centered at $1053 \mathrm{~nm}$ and zero degrees angle-of-incidence. The second sides of all samples were kept uncoated and uncontaminated. The DOP concentrations were calibrated to deposit contaminant levels ranging from $\mathrm{A} / 10, \mathrm{~A} / 5, \mathrm{~A}$, and $2 \mathrm{~A}$. Cleanliness level $\mathrm{A}$ is defined as a concentration of $1 \mathrm{microgram} / \mathrm{sq} \mathrm{cm}$ of a non-volatile residue. The numbers are multipliers or dividers of the concentration. A control sample (uncontaminated) was also included in the NVR test series.

The samples were given to the spectroscopist in a randomized, blind test. The samples were measured in transmission on a Cary 500 UV-VIS-nIR spectrophotometer. The scans were taken from 900 to $1200 \mathrm{~nm}$ at a rate of $300 \mathrm{~nm} / \mathrm{sec}$. The wavelength increment was $0.5 \mathrm{~nm}$. The slit width was $6 \mathrm{~mm}$ wide and the slit height selected at the "Full" setting (11 mm high).

After each transmission scan, the samples were rinsed with freon and the solvent waste collected in a pre-cleaned vial for subsequent analysis. The clean and dried samples were re-measured in transmission to determine the background. The spectroscopy data was exported into a spreadsheet for data reduction.

\subsection{Particulate Contamination}

In the particulate test, advantage is taken of the fact that the majority of the optics have a polished surface. A highintensity light incident on the optic can illuminate 10 micron-size particles as observed by an unaided eye. The light used in the particulate test is produced from a halogen lamp EYF $75 \mathrm{~W}, 12 \mathrm{~V}, 15^{\circ}$ cone source. The lamp is housed in a Halo Light housing Model 135L (L1974-X) [4]. Intensity of two lamps were measured with a light meter at a distance greater than the viewing distance so as not to saturate the meter, and a straight line was fitted to the data. As shown in Figure 3, the particulate inspection occurs at an estimated 4074 foot-candle intensity when the viewing distance is about 1 foot from the light source.

A glass window with a $1858 \mathrm{~cm}^{2}$ surface area was wiped with a conventional method used in the laser optics industry, a solvent dampened clean room wipe [5]. The wiping was performed in a laminar flow hood tested at a 
Class 100 rating. Clean room protocol was used, e.g. clean room smocks and shoe covers were worn, and clean room gloves [6] were used to handle the optics. The window was unwrapped in a "warehouse" area and was visibly contaminated with dust and packing debris. The window was cleaned and examined with the high intensity illumination source until no particulates were observed.

A special swipe tool was designed and built that would collect particles on a smooth surface. The details of the swipe procedure is referenced in MEL98-012 [3]. The swipe tool (Figure 4a) is a design to hold a piece of filter paper ( $60 \mathrm{~mm} \times 30 \mathrm{~mm}$ ) around a curved edge. The paper is held against a cushion so that constant pressure may be applied during the swipe. After swiping to collect the particulates, the paper is placed into a clear plastic cassette holder (Figure 4b). The holder protects the paper from further contamination, and keeps the paper flat for automatic counting. The cassette is placed on a computerized translation stage equipped with a video imaging system (Figure 4c). A video camera focuses through the plastic cassette lid and onto the paper. Contrast changes from the white background are counted and sized with a computer software routine.

Particulate swipes were taken of the clean window and after intentional-contamination with Arizona road dust. Due to the sensitivity of the inspection method, the road dust was filtered through clean room paper in order to reduce the particle size. About 5 grams of road dust was poured onto two sheet of clean room paper. The road dust was rubbed through the top sheet and collected with the second sheet. The second sheet was placed on a $30^{\circ}$ incline and dispersed into the air with a burst of filtered nitrogen. The optic was taken from its protected location, and waved gently through the air to collect the airborne dust. The optic, with its clear aperture perpendicular to the ground, was waved through the air in arc of 150 degrees and a 27 inch radius. When the optic was waved through the airborne dust four times, the optic was clearly contaminated as noted with a glance by both a trained and an untrained optics personnel. When the optic was waved through the airborne dust once, the personnel had to spend a few seconds inspecting the optic with the high intensity light source to view the particulates.

\section{RESULTS}

\subsection{Organic Validation}

The transmission scans of the DOP-contaminated fused silica substrates are presented in Figure 5. The contaminated surfaces have different spectral performances than that the control sample. In the range of contamination evaluated here, the transmission degraded with higher contamination levels. The transmittance differences between an uncontaminated and contaminated optic were determined at every wavelength interval. The averages and standard deviations for the transmission loss on the fused silica substrates are plotted in Figure 6. Comparing the control sample to that of the $A / 10$-contaminated sample, the results show that they are not 
significantly different. However, the A/5 and higher NVR levels results in a cleanly discernable transmission loss. Similar results were obtained with samples that have a hard dielectric anti-reflective coating before contamination with the DOP (Figure 7).

\subsection{Particulate Validation}

The particulate contamination conditions of the window are listed in Table 1. The first test condition was to determine how quickly the glass would become contaminated with Clean room dirt. The window was cleaned in a clean (Class 10,000) air environment of an optics assembly area and left exposed in that environment for a period of 2 months. The drawback with conducting this test in an assembly area is that the contamination comes in spurts. The optic had no observable contamination for weeks until uncontrolled events took place. Some of the known events were equipment repairs occurring near the optic, optic assembly, and outgassing/degreasing of some hardware near the optic. The optic was re-cleaned and Arizona road dust used to intentionally contaminate the optic. There were two levels of contamination: one that could be observed with a quick glance and the other that required viewing for a few seconds with the high intensity light source. The tests indicates that a Cleanliness Level 100 should be easily verified with a high intensity light source. When some particles are observed, the Cleanliness level is around Level 80. A conventional cleaning of an optic with a solvent damped tissue yields a Cleanliness Level of 50 or lower.

Table 1 Particulate validation with Arizona road dust and a high intensity light source

\begin{tabular}{|l|l|c|}
\hline Test & Condition & Cleanliness Level \\
\hline 1 & Cleaned and exposed for 2 months & 230 \\
\hline 2 & Contaminated and easily verified & 115 \\
\hline 3 & Contaminated and carefully verified & 78 \\
\hline 4 & Cleaned on Side 1 & 40 \\
\hline 5 & Cleaned on Side 2 & 48 \\
\hline
\end{tabular}

\section{SUMMARY}

Verification of non-volatile residue and particulates levels have been established for NIF small optics. The NVR levels verification is performed with a surrogate optic made of fused silica and measured with a UV-VIS-nIR spectrophotometer. The spectrophotometer is common test equipment that coating manufacturers use to verify spectral performance of laser-optics. NVR cleanliness levels to A/5 can be resolved. 
Particulate Cleanliness levels may be verified with a high intensity light source to below a Level 80 . When the optic has been recently cleaned using a solvent-damped tissue and inspected with the high intensity light source, the surface is at a Level 50 or better.

\section{AUSPICES}

This work was performed under the auspices of the U. S. Department of Energy by the University of California Lawrence Livermore National Laboratory under Contract W-7405-Eng-48.

\section{REFERENCES}

1. Department of Defense MIL-STD-1246C, Product cleanliness levels and contamination control program, Notice 3, 12 June 1998.

2. John Ertel, Non-Volatile Residue validation for NIF components, NIF5002325_OD98015.doc, MEL98015, 7 June 2000.

3. Jim Pryatel, Doug Ravizza, Irving F. Stowers, Surface Particle Cleanliness Validation by Swiping of NIF Components, NIF5002426_OD98012.doc, MEL99-012-OD, Sept. 24, 2001.

4. Cooper Industries, 400 Busse Road, Elk Grove Village, IL.

5. Berkshire Corp. DURX 770 cleanroom wipe, Great Barrington, MA.

6. Allegiance Healthcare Corp., McGraw Park IL, CP100 Nitrile Ambi, textured, beaded cuff, clean process 100. 


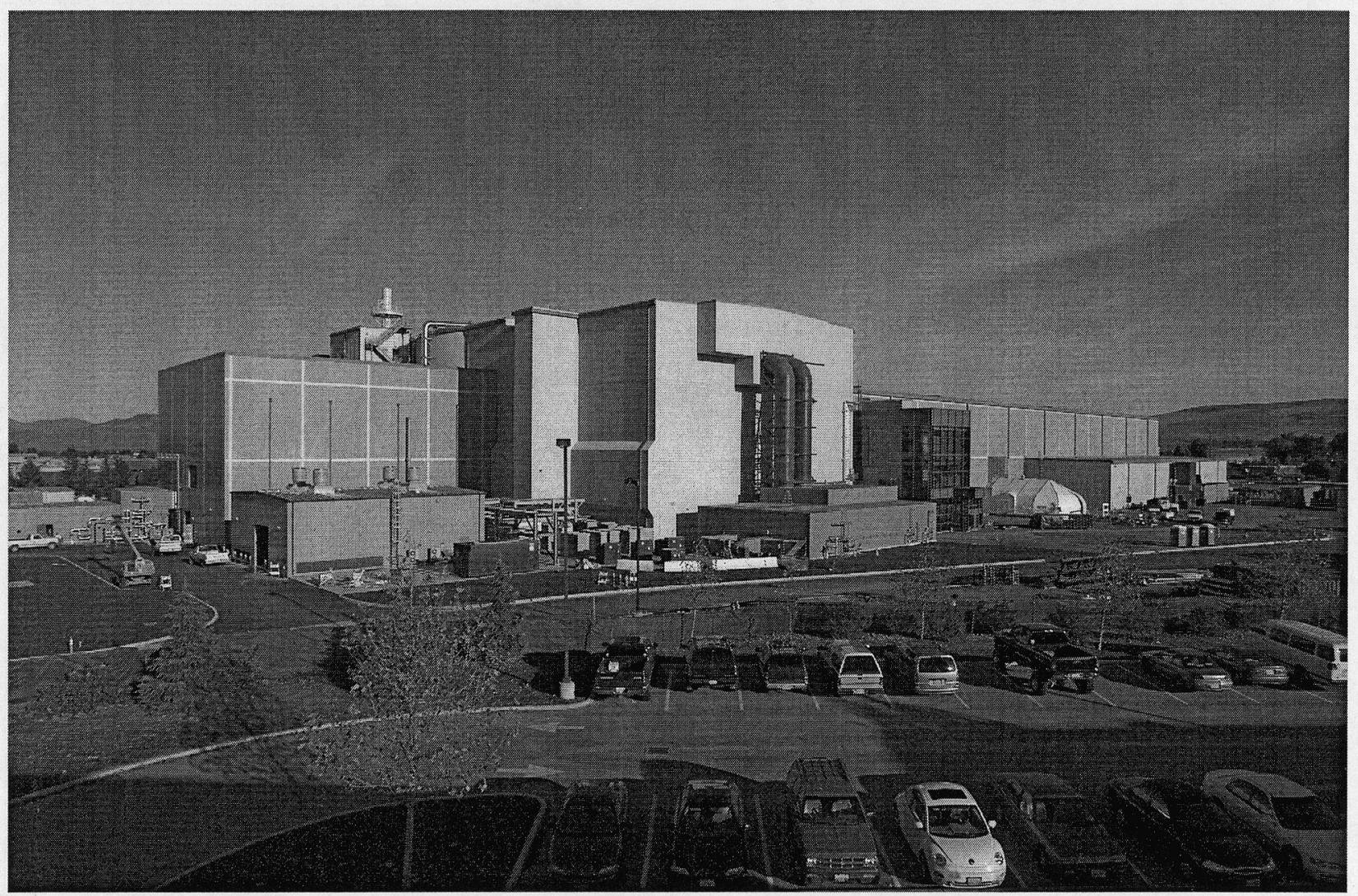

Figure 1 The NIF building. The Switchyard/Target Bay is in the center of the picture. The left side of the picture is the Diagnostic Building. The right side is the Laser Bay.

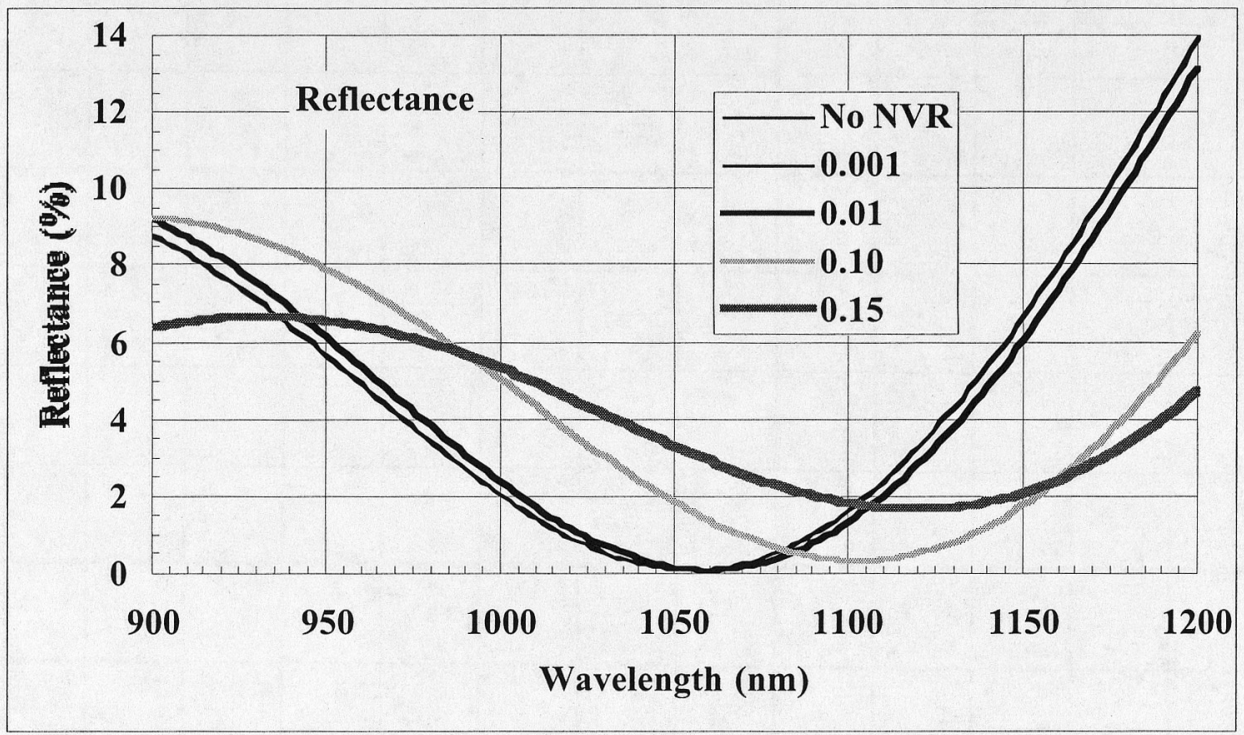

Figure 2 Estimated NVR effects on an anti-reflective coating. The coated design was optimized for a wavelength of $1053 \mathrm{~nm}$ and an incident angle of zero degrees. 


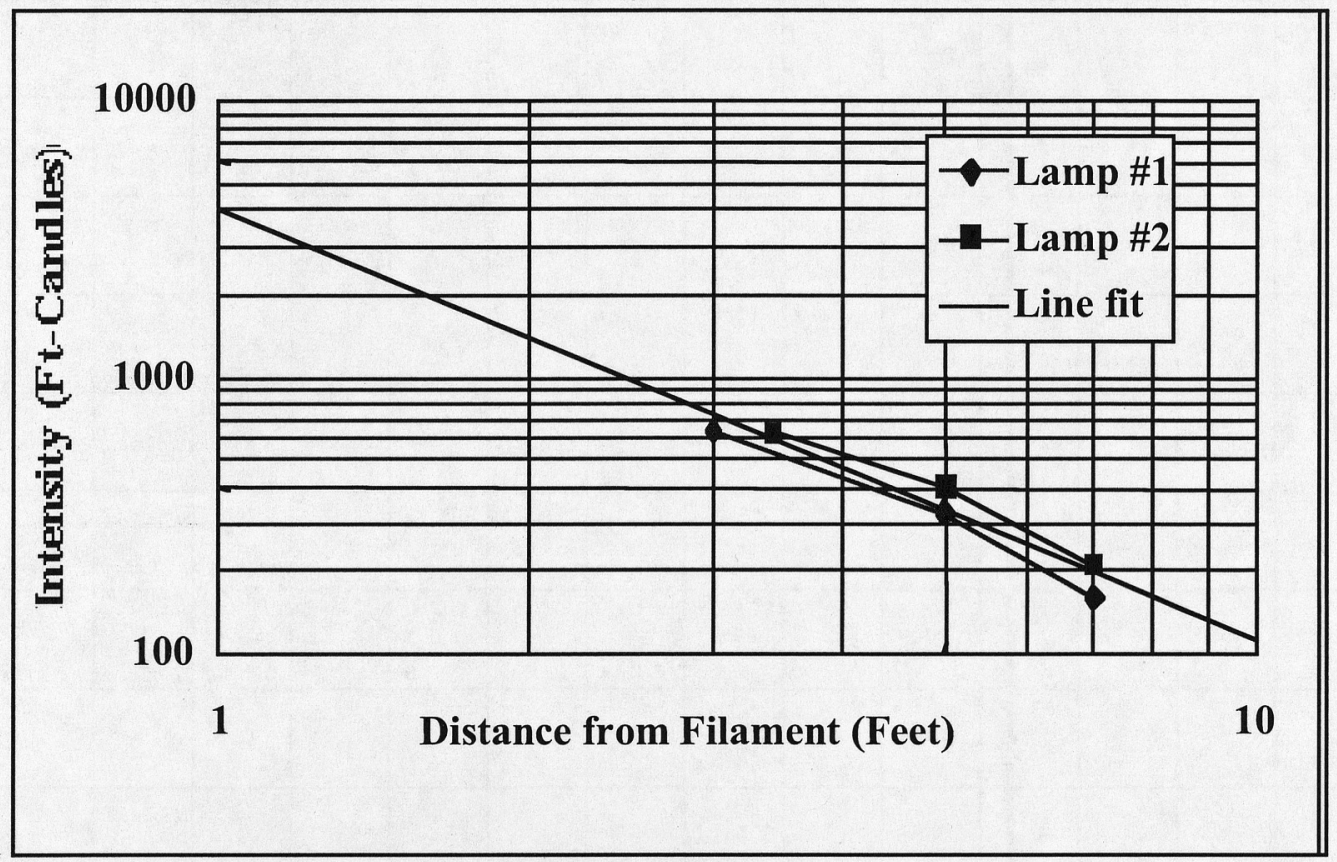

Figure 3 Lamp intensity for the inspection of clean optics.
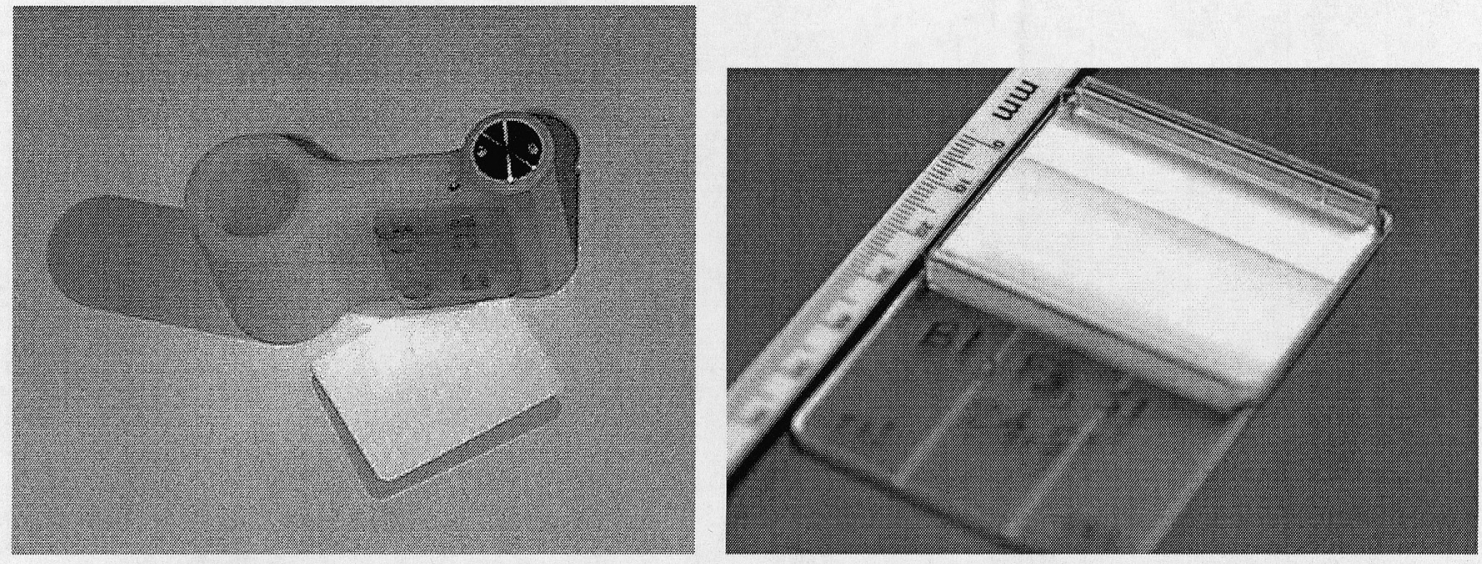

Figure 4 (a) Swipe tool and filter paper, and (b) Particulate measurement cassette. The swipe tool has a clip to that the holds the paper. The paper rolled around the smaller diameter, against a velcor cushion. The paper is dragged across a flat surface to collect particles. The paper is transferred to the cassette, sandwiched between a lid and bottom. The cassette also serves to seal the paper from further contamination and is an easy method of transporting the paper from the test site to the counter. 


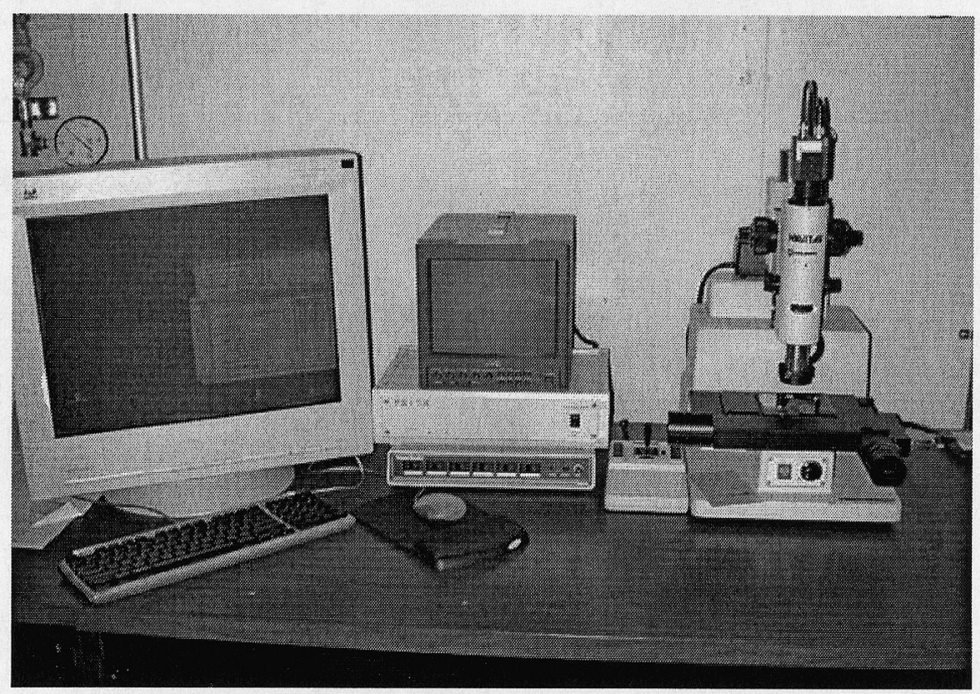

Figure 4c Automated particulate counting system.

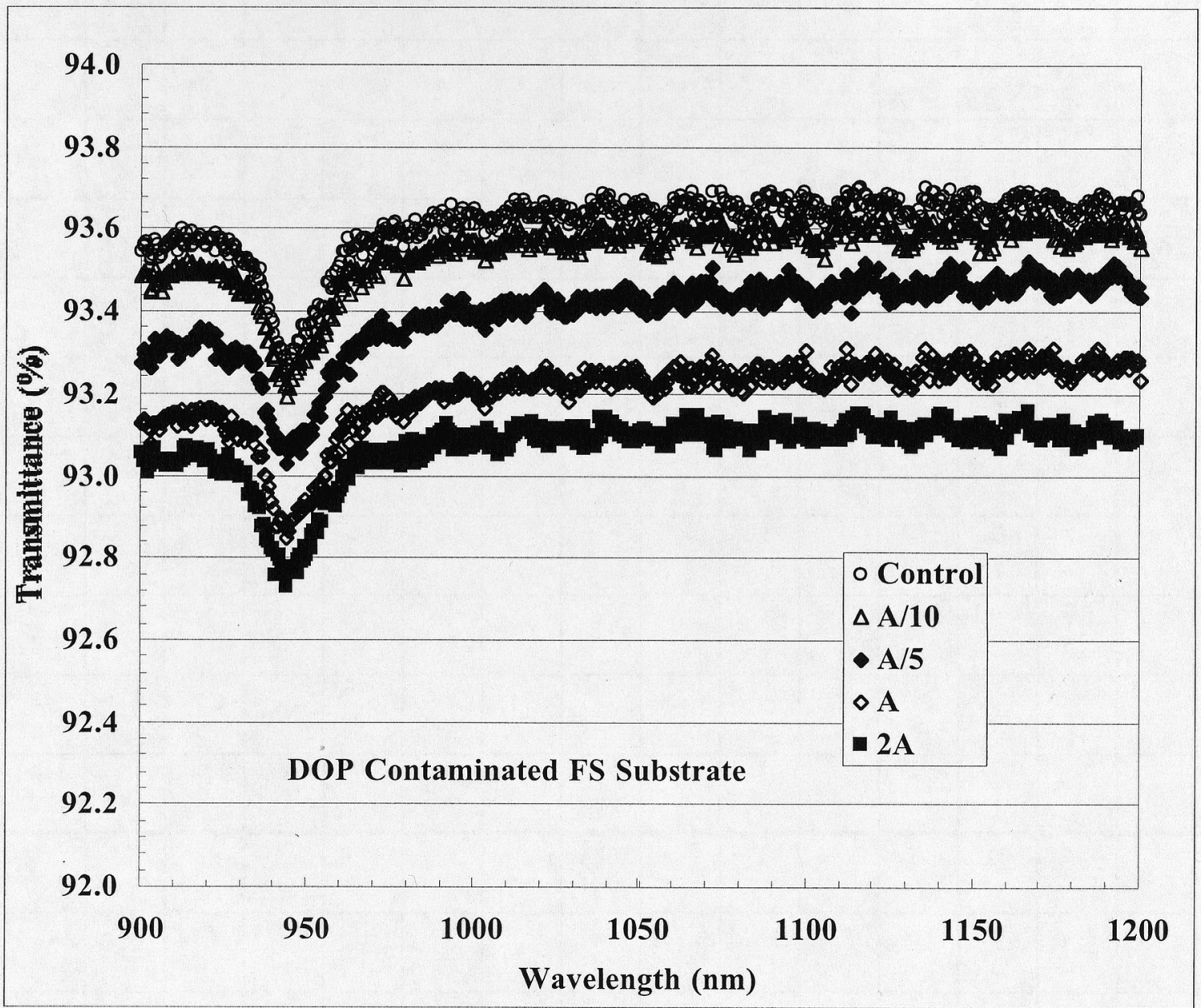

Figure 5 Transmittance of DOP-contaminated fused silica substrates. 


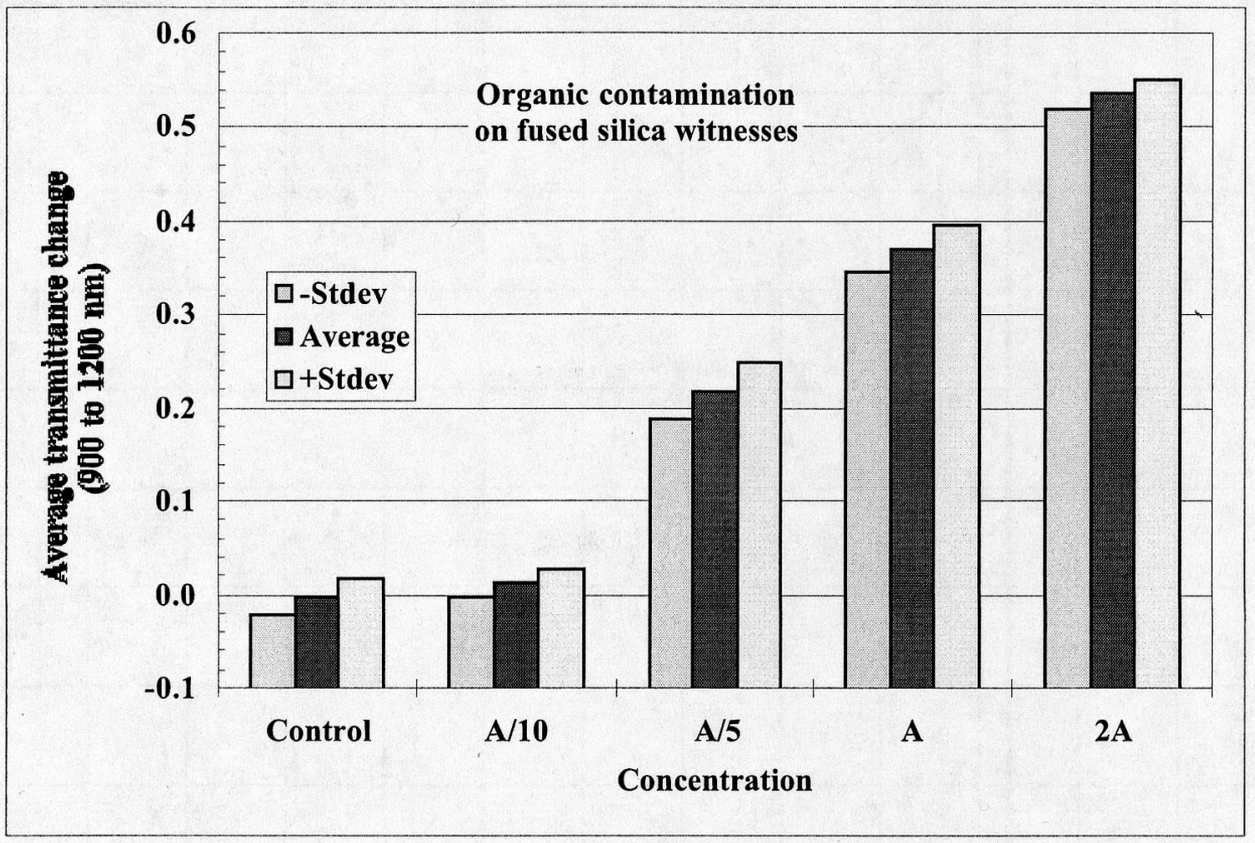

Figure 6 The average differential transmittances from organic contaminated fused silica substrates. The transmittance differences from 900 to $1200 \mathrm{~nm}$ were averaged, and the standard deviation calculated, from each of the scans. Each scan represents one of the contaminated fused silica samples.

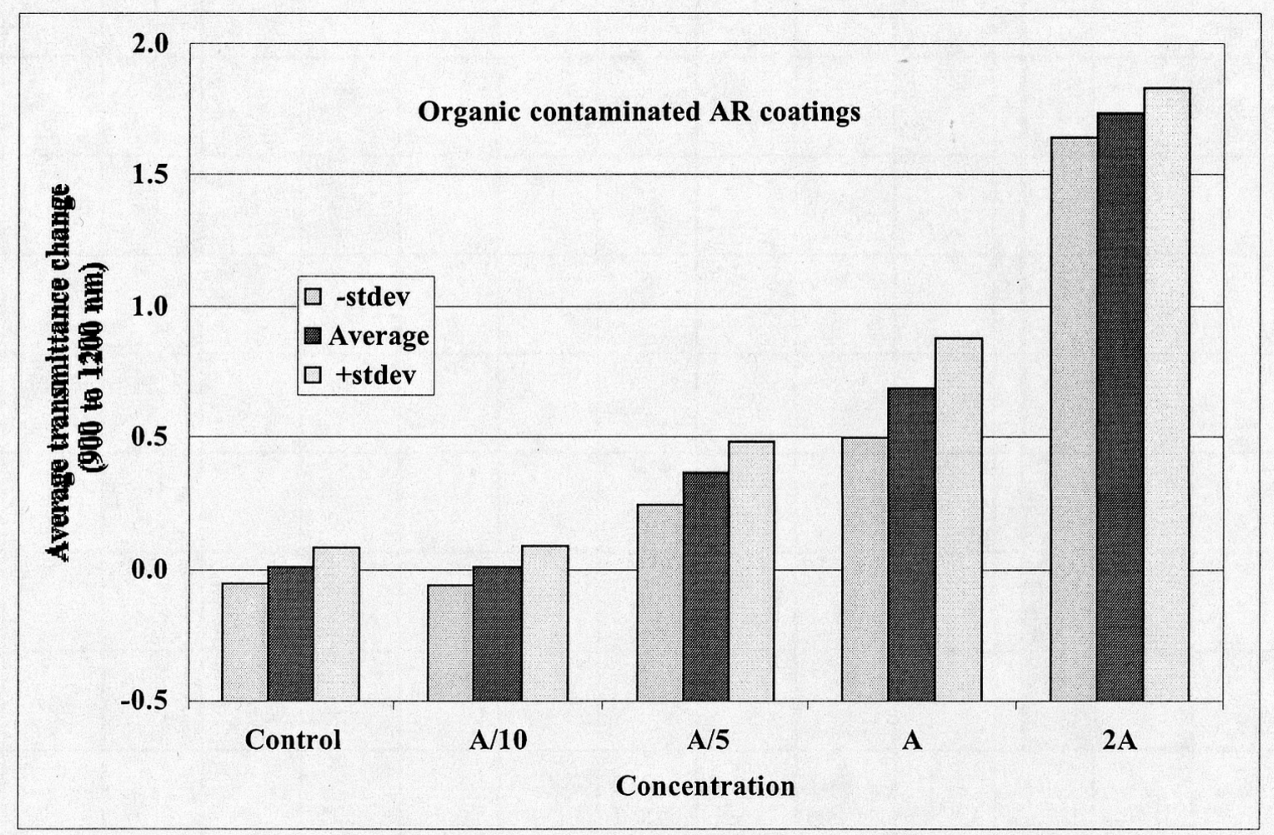

Figure 7 The average differential transmittances from organic contaminated anti-reflective coated surfaces. The transmittance differences from 900 to $1200 \mathrm{~nm}$ were averaged, and the standard deviation calculated, from each of the scans. Each scan represents one of the contaminated anti-reflective coated samples. 